Voix et Images

voixetimages

\title{
Un génie maladroit
}

André Brochu

Volume 28, numéro 1 (82), automne 2002

Noël Audet

URI : https://id.erudit.org/iderudit/000842ar

DOI : https://doi.org/10.7202/000842ar

Aller au sommaire du numéro

\section{Éditeur(s)}

Université du Québec à Montréal

\section{ISSN}

0318-9201 (imprimé)

1705-933X (numérique)

Découvrir la revue

\section{Citer cet article}

Brochu, A. (2002). Un génie maladroit. Voix et Images, 28(1), 171-174.

https://doi.org/10.7202/000842ar

Tous droits de reproduction, de rédaction et d'adaptation réservés 2002 C Université du Québec à Montréal
Ce document est protégé par la loi sur le droit d'auteur. L’utilisation des services d'Érudit (y compris la reproduction) est assujettie à sa politique d'utilisation que vous pouvez consulter en ligne.

https://apropos.erudit.org/fr/usagers/politique-dutilisation/
Cet article est diffusé et préservé par Érudit.

Érudit est un consortium interuniversitaire sans but lucratif composé de l'Université de Montréal, l'Université Laval et l'Université du Québec à Montréal. Il a pour mission la promotion et la valorisation de la recherche. https://www.erudit.org/fr/ 


\title{
Poésie
}

\section{Un génie maladroit}

\author{
André Brochu, Université de Montréal
}

Comme la nature, l'histoire littéraire a horreur du vide, et les professeurs ont longtemps souhaité trouver le chaînon manquant entre Nelligan et Saint-Denys Garneau. Albert Lozeau, les exotistes, Robert Choquette et Alfred DesRochers, malgré leurs mérites, ne faisaient guère le poids.

Il est pourtant un nom qui réémerge périodiquement depuis les années 1950, et dont l'œuvre a été remise en circulation voilà plus de trente ans. Il s'agit de Jean Aubert Loranger, auteur, au début des années 1920 , de deux recueils ${ }^{1}$ qui présentent beaucoup d'intérêt, à défaut d'emporter la conviction du lecteur comme le fait l'œuvre des célébrités entre lesquelles il s'encadre. Sur les plans formel et thématique, la modernité d'une telle poésie ne fait aucun doute et contraste curieusement avec une abondante production, plus tardive, de contes aux accents résolument régionalistes ${ }^{2}$.

Voilà qu'on réédite l'essentiel de l'œuvre poétique ${ }^{3}$. Dans une présentation qui équivaut à une véritable étude critique, par la rigueur et l'intelligence des aperçus, Dominique Robert (elle-même poète talentueuse) situe fort bien l'entreprise de Loranger. Elle attire surtout l'attention sur l'influence de l'unanimisme, mouvement qui répondait au désir de limiter les excès irrationalistes du symbolisme tout comme le mouvement parnassien, soixante ans plus tôt, s'était constitué en réaction contre le romantisme. Elle parle aussi, en se référant à une étude de Claude Filteau, de l'empirisme psychologique qui a permis au jeune poète, «trop pessimiste et solitaire» (p. 16) pour devenir un porte-parole de la foule unanime, de trouver son registre personnel. L'énumération des motifs poétiques, «le cœur, le départ des bateaux, les anneaux de fer des quais, le fleuve, l'amplitude, les phares $[\ldots]$ ), complète fort bien les vues sur le mixte d'unanimisme concret, qui comporte une approche rationnelle du monde, et d'expérimentation psychologique qui la subjectivise et l'individualise.

Signets et autres poèmes reprend d'abord la section des Atmosphères (1920) intitulée «Signets» et qui est formée de poèmes en vers libres ou en prose fort aérée, puis l'intégralité des Poëmes (ici, l'orthographe du titre est modernisée) de 1922. Dominique Robert laisse de côté les autres textes des Atmosphères, en particulier le plus connu, «Le passeur» qui évoque dans la forme prose l'existence d'un moderne nocher condamné à l'itérativité, en l'occurrence à une quête sans horizon. De la sorte, Signets et autres poèmes regroupe tout ce qui, dans l'œuvre de Loranger, s'apparente à la pratique du vers libre et constitue certes la plus audacieuse qu'on puisse trouver dans nos 
lettres avant Saint-Denys Garneau. La libération est plus marquée à l'égard de la rime que du mètre, les vers étant le plus souvent isosyllabiques.

On ne trouve pas, chez Loranger, ces accents inoubliables qui font le prix des poèmes de Nelligan ou de Garneau. Le discours qu'il tient est pourtant personnel et dépourvu, notamment, de la rhétorique qui emplit les strophes claironnantes ou pieuses de la poésie du terroir. Le jeune poète parle de lui-même sans apprêt, de son désir d'évasion qui prend la forme d'un départ définitif, selon les moyens de l'époque c'est-à-dire en bateau, mais aussi du besoin de retour qui combat ce désir. Partir, rester sont les deux faces de la même médaille, celle de l'existence malaisée, dont le seul enchantement consiste dans une sorte de conscience métaphysique du moi impossible:

J'avais perdu mes limites, Fondu que j'étais

Avec l'épaisseur de l'ombre. - Comme c'est pareil,

Ouvrir ou fermer les yeux (p. 67).

Une telle strophe, fort belle, se distingue par sa clarté et son originalité. Elle annonce les tourments ontologiques de Saint-Denys Garneau, introduit une certaine abstraction en poésie (perte des limites), en relation avec le sentiment de l'ultra-concret - l'ombre est épaisse et on s'y fond, elle est le corps continué, moi et monde se compénètrent. Audace et limpidité absolue de la notation finale: «c'est pareil,/Ouvrir ou fermer les yeux ». La présence et l'absence au monde sont une seule et même chose, ce qui revient à affirmer le privilège de l'intériorité.

Il s'en faut de beaucoup que tout soit aussi réussi. Souvent, en lisant
Loranger, on éprouve quelque malaise devant l'expression d'une intuition forte, mais dont la formulation reste sommaire, exposant le texte aux périls de la prose ou de l'incorrection. Il en va ainsi d'un poème souvent cité, "Je regarde dehors par la fenêtre» (p. 29), où le poète contemple le paysage en se collant à la vitre, et la nature se trouve ainsi pétrifiée et dominée par celui qui la regarde. Intérieur et extérieur, moi et monde se font équilibre, dans une sorte de transe immobile qui confronte le sujet «monstrueusement énorme » au «dehors solidarisé ». L'authenticité d'une telle expérience immédiate de soi, du corps, du monde, fait événement dans notre poésie. Malheureusement, l'écriture n'est pas tout à fait à la hauteur, et des énoncés tels que «Je regarde dehors par la fenêtre», quasi pléonastiques, ou «Je suis énorme, [...] Monstrueusement énorme », d'une assez plate redondance sémantique, ne sont pas sans décevoir. Quant au «dehors solidarisé», il étonne un peu - s'agit-il bien de la solidarité des éléments qui le constituent même si «Ma main, elle seule, cache trois maisons», ou d'une approximation pour désigner la solidité de la vitre transférée au paysage ${ }^{4}$ ?

Bref, chez Loranger, on ne sait jamais très bien si l'on est en présence d'une idée poétique forte ou d'une faiblesse stylistique. Un autre poème, qui inaugure la petite suite du «Retour de l'enfant prodigue», commence par ce vers: «Ouvrez cette porte où je pleure» (p. 83). Le «où », qui a un sens locatif, est à la limite de l'incorrection: on pleure à ou devant la porte, où signifiant plutôt dans ou sur. Sans doute, la fron- 
tière entre dedans et dehors, on l'a vu à propos du poème précédent, tend à devenir elle-même le lieu de toute réalité, à s'incorporer l'espace intime et l'espace extérieur, ce qui permet le triomphe du moi sur le monde. Passons donc sur ce «où » laconique, qui suggère beaucoup plus qu'il ne dit.

Le vers prend tout de même une coloration nettement négative si on le rapproche du début d'un poème de Guillaume Apollinaire, certainement connu de Loranger, où il est question aussi de retour après une longue absence, «Le voyageur ${ }^{5}$ »: «Ouvrez-moi cette porte où je frappe en pleurant». L'incipit de Loranger apparaît comme la reprise en raccourci d'un alexandrin qui, lui, ne comporte pas de singularité syntaxique, mais est porteur d'une mélancolie qui s'exprimera de façon originale dans le vers suivant, encore un alexandrin (qui constitue une strophe à lui seul) : «La vie est variable aussi bien que l'Euripe». On voit qu'Apollinaire ne dédaigne pas, lui non plus, les vers comptés. Mais l'effet de surprise chez lui tient moins à une syntaxe contractée qu'à la succession elliptique des phrases poétiques.

La parenté entre les incipits des deux poèmes n'est sûrement pas due au hasard. Non seulement les thèmes $d u$ voyage et du retour sont-ils au cœur des textes, mais ceux-ci adoptent la même forme circulaire (retour des premiers vers à la fin).

On peut en conclure à la présence d'influences chez le jeune poète québécois ${ }^{6}$, ce qui est tout à fait dans l'ondre des choses. Une lecture attentive permet tout de même de trouver chez lui, entre génie et maladresse, des vers pleins de délicat mystère:
Le soir pense dans son ombre Comme des yeux clos,

Des pensées tristes lui naissent Comme des hiboux.

- J'avoue la nuit et l'attente

(p. 76).

Il aurait suffi d'un projet poétique un peu plus soutenu pour que Loranger s'inscrive parmi les grands initiateurs de la modernité poétique au Québec.

***

Un livre aux allures d'album réunit une vingtaine de poètes français et autant de poètes québécois autour d'un thème commun: la France. Réalisé par Claudine Bertrand, dévouée artisane des rapprochements et des échanges entre les deux pays, La France des poètes ${ }^{7}$ invite à une réflexion entre des pratiques du texte à la fois différentes et convergentes. La France des Français correspond le plus souvent à un coin de province, ou encore à cet immense lieu commun qu'est Paris, mais celui des quartiers, et c'est le nid d'une enfance ou le décor des fidélités quotidiennes, plutôt que le pays des ferveurs nationales, qui fait l'objet d'une célébration. Un seul participant, Michel Camus, ignore carrément le thème et une autre, Victoria Thérame, évoque la patrie comme telle, terre de liberté.

Les Québécois abordent plutôt la France à travers des souvenirs liés à des expériences personnelles, amours plus ou moins heureuses, parfois recherche des origines. La France peut apparaitre comme le pays des commencements (Cécile Cloutier, Madeleine Ouellette-Michalska), ou le lieu de grands fastes religieux (Claudine Bertrand, Jocelyne Felx) ou culturels. 
Curieusement, à travers ces exaltations sans surprise, une note morbide lui est souvent associée. Denise Desautels évoque, en contrepoint du rappel d'une amitié, les trois Leçons de ténèbres de Delalande (p. 75-77). Pour Louise Dupré, Paris «répand/le parfum de la terre/où lentement tu te décomposes » (p. 81) et se résume finalement au cimetière où repose l'être aimé. La Notre-Dame de Jocelyne Felx, après de claires louanges, s'assombrit soudain et «Tout est nocturne et confus, Dame au fruit qui s'achève en nuit» (p. 86). Pierre Ouellet, inspiré par le nom de Limoges, confie: «On me limoge [sic] dans ces profondeurs d'où rien ne refait surface: tout reste creux, s'étend, gorge, abîme à vie»(p. 95). Les «Sept cimetières marins» de Bernard Pozier, joints au cimetière marin de Douarnenez où repose Georges Perros, évoqué par Jean Royer (p. 107, 109), compléteront la noire géographie d'une mère patrie surannée, où le Québec semble trouver plus de raisons de mourir que de vivre.

1. Jean Aubert Loranger, Les atmosphères, Le passeur, Poëmes et autres proses, Montréal,
L.-Ad. Morissette, 1920, 62 p.; et Poëmes, Montréal, L-Ad. Morissette, 1922, 112 p.

2. Bernadette Guilmette décrit cette production considérable (environ 150 textes dont la plupart font partie d'un cycle consacré à un héros de village, Joë Folcu) dans «À la recherche du régionalisme et autres contes de Jean Aubert Loranger», Dictionnaire des œuvres littéraires du Québec, t. II, 19001939, Montréal, Fides, 1980, p. 14-21.

3. Jean Aubert Loranger, Signets et autres poèmes, choix et présentation de Dominique Robert, Montréal, Les Herbes rouges, coll. «Five O’Clock», 2001, 116 p.

4. La maladresse est encore plus évidente dans des collocations telles que les «nonrons»du tambour (p. 30) ou «le silence/Dont mon rêve s'était parqué »(p. 60).

5. Guillaume Apollinaire, "Alcools», dans Euvres poétiques, Paris, Gallimard, coll. «La Pléiade», 1959, p. 78-80.

6. On relève encore celle-ci: «Toc, toc, toc, les sabots cognent/Sur les pavés de la rue» (Loranger, p. 93) et «Toc toc Il a fermé sa porte $[. .$.$] Tu viens de toquer à sa porte/Et$ trotte trotte/Trotte la petite souris » (Apollinaire, p. 127).

7. La France des poètes, Montréal, Trait d'union, 2002, 124 p. Textes d'A. Appercelle, M.-C. Bancquart, M. Camus, A. Chedid, S. Clancier, F. Combes, S. Dagtekin, J. Darle, J.-P. Faye, C. Helft, D. Leuwers, F. Montmaneix, B. Noël, J. Orizet, A. Salager, V. Thérame, P. Vieuguet, de France; et P. Bélanger, C. Bertrand, L Blouin, D. Boucher, C. Cloutier, G. Cloutier, D. Desautels, S. Despatie, L Dupré, J. Felx, D. Fournier, L Francœur, A. Molin Vasseur, P. Ouellet, M. OuelletteMichalska, B. Pozier et J. Royer, du Québec.

\section{Dramaturgie}

\section{Sur la route}

\section{Lucie Robert, Université du Québec à Montréal}

Quand une logique de la fuite ou de la quête se substitue au conflit d'espaces qui caractérise le théâtre de convention, l'espace scénique «n'est plus conçu comme une co- quille à l'intérieur de laquelle certains arrangements sont permis ${ }^{1}$ », mais comme un entre-deux, un sas entre deux espaces hors scène, évoqués ou racontés par les personnages. La dra- 